\title{
The Crystal Structure of $\mathbf{P d}_{15} \mathbf{P}_{2}$
}

\author{
YVONNE ANDERSSON
}

Institute of Chemistry, University of Uppsala, Box 531, S-751 21 Uppsala, Sweden

The crystal structure of $\mathrm{Pd}_{15} \mathrm{P}_{2}$ has been determined and refined from 2080 three-dimensional single-crystal X-ray diffractometer data to an $R\left(F^{2}\right)$ value of 0.092 . The space group is $R \overline{3}$ (No. 148). The hexagonal unit cell, of dimensions $a=7.1067(2) \AA, c=17.0867(6) \AA$, con. tains three formula units. The structure is related geometrically to the $\alpha$-boron structure.

In the $\mathbf{P d}-\mathbf{P}$ system Gullman ${ }^{1}$ found a very palladium-rich intermediate phase which forms peritectically at $799^{\circ} \mathrm{C}$ and has the approximate composition $\operatorname{Pd}_{8} \mathbf{P}$. In the present paper the results from a crystal structure analysis of this phase are presented. The ideal crystallographic formula is $\mathrm{Pd}_{15} \mathrm{P}_{2}$.

\section{EXPERIMENTAL}

Preparation. Starting materials were palladium powder (Heraeus, Germany) with a claimed purity of $99.9 \%$ and red phosphorus of purity greater than $99 \%$. Polycrystalline $\mathbf{P d}_{15} \mathbf{P}_{2}$ samples were prepared in exactly the same manner as described by Gullman.1 To obtain single crystals for $\mathrm{X}$-ray investigations, pressed pellets of well-mixed palladium and phosphorus powder were heated in evacuated silica tubes at $830^{\circ} \mathrm{C}$ for two days and $795^{\circ} \mathrm{C}$ for five months. In spite of the long heattreatment the sample contained $\mathrm{Pd}$ and $\operatorname{Pd}_{6} \mathrm{P}$ in addition to $\mathrm{Pd}_{15} \mathbf{P}_{2}$. Out of the crushed sample good crystals could be obtained, even though they were all of an irregular needle shape.

X-Ray powder investigations. Powder diffraction patterns were obtained with focusing Hägg-Guinier-type cameras using $\mathrm{CrK} \alpha_{1}$ or $\mathrm{CuK \alpha _{1 }}$ radiation and silicon $(a=5.431065 \AA)^{2}$ or germanium $(a=5.65806 \AA)$ as calibration standards. Cell parameters were refined by the least-squares method using the local program CELNE. ${ }^{3}$ Powder diffraction intensity data were obtained by measuring Hägg-Guinier photographs on an automatic drum densitom- eter (SAAB model 2), using a method similar to that described by Malmros and Werner.4

Single crystal investigations. Single crystal diffraction intensity data were recorded on a Stoe four-circle diffractometer with a graphite monochromator using $M o K \alpha$ radiation. The intensity measurements were made using the $\omega-2 \theta$ step scan technique, to a maximum in $2 \theta$ of $100^{\circ}$. For symmetry control, symmetry. related reflexions were measured in the region $0 \leq 2 \theta \leq 40^{\circ}$ and their hexagonal indices were limited by $-3 \leq h \leq 5,-5 \leq k \leq 3$ and $-12 \leq l \leq$ 12. For $2 \theta>40^{\circ}$ the hexagonal indices ranged between $0 \leq h \leq 15,-13 \leq k \leq 0$ and $-36 \leq l \leq$ 36. Instrumental stability and the crystal setting were checked regularly using three standard reflexions remeasured every 50 reflexions. The weakest of these three, $(01 \overline{7})$, was found to vary somewhat erratically, while the other two remained within expected fluctuations.

Absorption corrections were applied to the single crystal data. The shape of the crystal was approximated to a triangular prism bounded by $\{\overline{11}\}, \quad\{\overline{3} 4 \overline{6}\},\{0 \overline{1} 7\},\{116\}$ and $\{3 \overline{2} \overline{9}\}$ planes. The length of the crystal was $0.120 \mathrm{~mm}$ and the edges of the triangular cross-sections ranged from 0.033 to $0.057 \mathrm{~mm}$. The minimum and maximum transmission factors were 0.157 and 0.789 , using a calculated linear absorption coefficient of $259 \mathrm{~cm}^{-1}$.

The calculations were performed on IBM $370 / 155$ and IBM 1800 computers using crystallographic programs listed in Ref. 5.

\section{STRUCTURE ANALYSIS}

The powder diffraction data obtained for $\operatorname{Pd}_{15} P_{2}$ were in very good agreement with Gullman's ${ }^{1} \mathbf{P d}_{8} \mathbf{P}$ results. The $\mathbf{P d}_{15} \mathbf{P}_{2}$ powder data as obtained in this study are given in Table 1 . Using the information from Weissenberg photographs the powder pattern could be indexed with a hexagonal cell of dimensions $a=7.1067(2)$ $\AA$ and $c=17.0867(6) \AA$ at $25^{\circ} \mathrm{C}$ (numbers in parentheses are the calculated standard devia- 
Table 1. Powder diffraction data for $\mathrm{Pd}_{15} \mathrm{P}_{2}$. (Guinier-Hägg camera, $\mathrm{CuK \alpha _{1 }}$ radiation, internal calibration standard silicon $a=\mathbf{5 . 4 3 1 0 6 5}$ $\AA$, intensities from film scanner.)

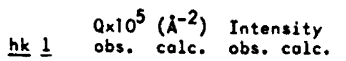

\section{1}

$\begin{array}{ll}10 & 1 \\ 0 & 3 \\ 01 & 2\end{array}$

112

104

$\begin{array}{lll}0 & 1 \\ 1 & 1 & 3\end{array}$

1123

$\begin{array}{ll}01 & 5 \\ 20 & 2 \\ 00 & 6\end{array}$

$\begin{array}{ll}02 & 4 \\ 23 & 1 \\ 21 & 1\end{array}$

- overlopped by Fd.
Q $\times 10^{5}\left(\AA^{-2}\right)$ Intensity hk 1 obs. colc. obs. colc.

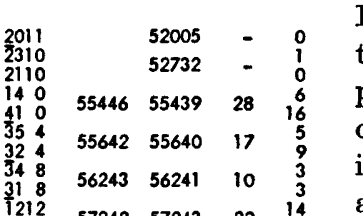
$\begin{array}{llll}57242 & 57243 \quad 22 & 14\end{array}$

tions). No significant changes in the unit cell dimensions were observed for different samples.

Weissenberg photographs taken with the crystal rotating about the hexagonal $a$-axis showed that the rhombohedral condition $-h+$ $k+l=3 n$ was obeyed for all reflexions. Since only a three-fold symmetry was observed, most likely space groups were $R 3$ and $R \overline{3}$. The cell volume and the approximate composition $\operatorname{Pd}_{8} \mathrm{P}$ suggested a unit cell content of about 48 palladium and six phosphorus atoms.

In the preliminary structure analysis, the Harker section $P(u, v, 0)$ of the Patterson function indicated $R \overline{\mathbf{3}}$ space group symmetry with palladium atoms in two general positions. Space considerations and the Harker section $P(u, 0, w)$ indicated two further palladium sites, in $6 c$ and $3 b$, and one phosphorus site in $6 c$. The ideal crystallographic composition should accordingly be $\operatorname{Pd}_{15} \mathrm{P}_{2}$. Since the structure model thus derived appeared quite reasonable from the crystal chemical point of view, least-squares refinements of the parameters were immediately started. The positional parameters, a scale factor and individual isotropic temperature factors were refined using a full-matrix leastsquares program. ${ }^{5}$ The atomic scattering factors and the dispersion correction factors were taken from Ref. 6. After three cycles a conventional $R$-value of 0.106 was obtained based on the 1495 strongest reflexions. Since the structure proposal seemed to be correct, a linear absorption coefficient was calculated, and an absorption correction applied to the observed intensities. In order to correct for extinction effects only reflexions having identical indices were averaged.

A series of least-squares refinements on both $F$ and $F^{2}$ were performed. The function minimized was $w\left(\left|F_{\mathrm{o}}{ }^{n}\right|-\left|F_{\mathrm{c}}{ }^{n}\right|\right)^{2}$ with $n=1$ or 2 , respectively. Weights were assigned to the reflexions according to the formula $w^{-1}=\sigma^{2}$ $\left(F_{\mathrm{o}}{ }^{n}\right)+\left(p_{n} F_{\mathrm{o}}{ }^{n}\right)^{2}$, where $\sigma^{2}\left(F_{\mathrm{o}}{ }^{n}\right)$ is based on counting statistics and the empirical factor $p_{n}$ was set to $p_{1}=0.02$ and $p_{2}=0.03$. An isotropic extinction parameter, according to the expression by Coppens and Hamilton " based on approximations introduced by Zachariasen, and anisotropic temperature factors for the palladium atoms was introduced. 32 strong reflexions were assigned zero weight in the refinements because their extinction correction factors did not satisfy the condition for Zachariasen's approximations. The value for the extinction parameter $g^{2}$ finally obtained was $0.50(5)$. For the 2080 reflexions refined the following agreement factors were obtained, 
Table 2. Structure data for $\mathrm{Pd}_{15} \mathbf{P}_{2}$, including anisotropic thermal parameters $\beta_{\mathrm{ij}}\left(\times 10^{5}\right)$ for the palladium atoms. The form of the temperature factor is $\exp \left(-\beta_{11} h^{2}-\beta_{22} k^{2} \ldots-2 \beta_{12} h k \cdots\right)$.

\begin{tabular}{|c|c|c|c|c|c|c|c|c|c|c|}
\hline Atom & $\begin{array}{l}\text { Posi- } \\
\text { tion }\end{array}$ & $x$ & $y$ & $z$ & $\beta_{11}$ & $\beta_{22}$ & $\beta_{33}$ & $\beta_{12}$ & $\beta_{13}$ & $\beta_{23}$ \\
\hline $\mathbf{P d}(1)$ & $18 f$ & $0.40049(7)$ & $0.28437(7)$ & $0.96339(2)$ & $556(8)$ & $487(8)$ & $61(1)$ & $232(6)$ & $-6(2)$ & $-14(2)$ \\
\hline $\mathrm{Pd}(2)$ & $18 f$ & $0.25807(7)$ & $0.23813(7)$ & $0.79537(2)$ & $488(8)$ & $589(8)$ & 59(1) & $274(6)$ & $13(2)$ & $-7(2)$ \\
\hline $\mathrm{Pd}(3)$ & $6 c$ & 0 & 0 & $0.07941(4)$ & $542(8)$ & $542(8)$ & $56(2)$ & $271(4)$ & 0 & 0 \\
\hline $\operatorname{Pd}(4)$ & $3 b$ & 0 & 0 & $1 / 2$ & $440(10)$ & $440(10)$ & $56(2)$ & $220(5)$ & 0 & 0 \\
\hline & $6 c$ & 0 & 0 & $0.28552(16)$ & & & & & & \\
\hline
\end{tabular}

a Isotropic temperature factor $0.96(3)\left(\AA^{2}\right)$.

$R\left(F^{2}\right)=0.092, R(F)=0.066$ and $R_{\mathrm{w}}\left(F^{2}\right)=0.144$, where

$R\left(F^{n}\right)=\Sigma|| F_{\mathrm{o}}{ }^{n}|-| F_{\mathrm{c}}{ }^{n}|| / \sum\left|F_{\mathrm{o}}{ }^{n}\right|$ and

$R_{\mathrm{w}}\left(F^{n}\right)=\left[\sum w\left(\left|F_{\mathrm{o}}{ }^{n}\right|-\left|F_{\mathrm{c}}{ }^{n}\right|\right)^{2} / \sum w\left|F_{\mathrm{o}}{ }^{n}\right|^{2}\right]^{\frac{1}{2}}$

In subsequent refinements the occupancy factors were varied but the refinements invariably terminated with insignificant deviations from full occupancy. Experimental errors in the geometrical description of the crystal, together with the very strong absorption, are probably responsible for the comparatively high final values obtained for the agreement factors.

The final structure data obtained are pre. sented in Table 2. A table of observed and calculated structure factors can be obtained from the author on request.

\section{DESCRIPTION AND DISCUSSION OF THE $\mathrm{Pd}_{15} \mathrm{P}_{2}$ STRUCTURE}

Calculated interatomic distances are given in Table 3. Each palladium atom coordinates 12-15 palladium and phosphorus neighbours, and the phosphorus atoms have nine palladium neighbours. The structure can be described in terms of slightly distorted icosahedral building elements with six $\operatorname{Pd}(1)$ and six $\operatorname{Pd}(2)$ atoms at the corners and one $\operatorname{Pd}(4)$ atom at the centre. The icosahedra are arranged in nearly the same way as spheres in cubic close-packing.

In the "cubic close-packing" of palladium icosahedra in $\operatorname{Pd}_{15} \mathrm{P}_{2}$, the "octahedral holes" are filled with pairs of $\operatorname{Pd}(3)$ atoms and the "tetrahedral holes" with phosphorus atoms.

The "octahedral hole" is illustrated stereo. scopically in Fig. 1. It is actually a polyhedron with 18 palladium atoms at the vertices: each of the surrounding six palladium icosahedra contributing three corner atoms to this poly. hedron.

The "tetrahedral hole" is illustrated stereo. scopically in Fig. 2. The central phosphorus atom is surrounded by nine palladium neigh. bours, six of them situated at the corners of a distorted triangular prism, and the remaining three more remotely outside the quadrilateral faces of the prism. This kind of environment

Table 3. Interatomic distances in $\operatorname{Pd}_{15} P_{2}(\AA)$. The maximum standard deviation obtained was $0.0008 \AA$ for $\mathrm{Pd}-\mathrm{Pd}$ distances and 0.0018 $\AA$ for P-Pd distances. Distances shorter than 3.5 $\AA$ are listed.

\begin{tabular}{|c|c|c|c|}
\hline 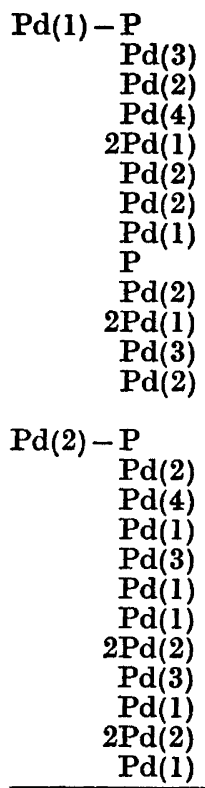 & $\begin{array}{l}2.263 \\
2.640 \\
2.730 \\
2.825 \\
2.828 \\
2.857 \\
2.875 \\
2.937 \\
2.990 \\
3.007 \\
3.021 \\
3.219 \\
3.352 \\
\\
2.244 \\
2.638 \\
2.710 \\
2.730 \\
2.775 \\
2.857 \\
2.875 \\
2.934 \\
2.940 \\
3.007 \\
3.061 \\
\mathbf{3 . 3 5 2}\end{array}$ & $\begin{array}{r}\operatorname{Pd}(3)-3 P d(1) \\
P \operatorname{Pd}(3) \\
3 P d(2) \\
3 P d(2) \\
3 P d(1)\end{array}$ & $\begin{array}{l}2.710 \\
2.825 \\
\\
2.244 \\
2.263 \\
2.990\end{array}$ \\
\hline
\end{tabular}

Acta Chem. Scand. A 31 (1977) No. 5 

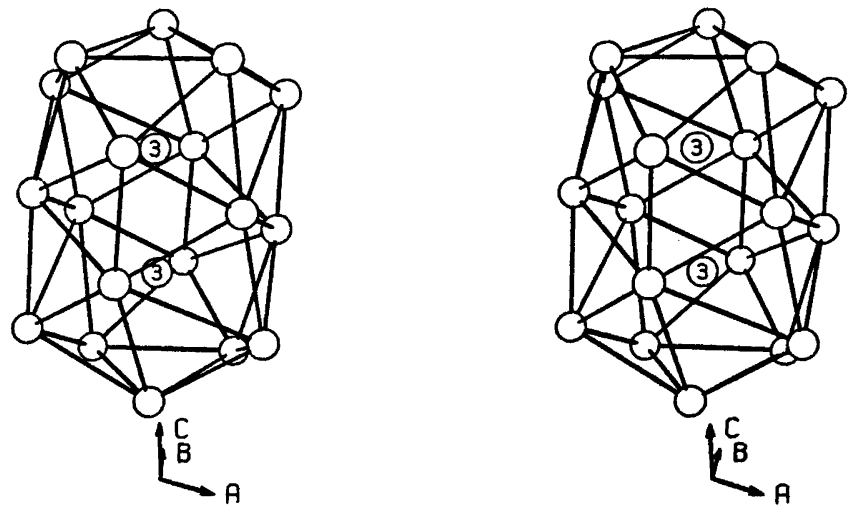

Fig. 1. The "octahedral hole" enclosing the two $\operatorname{Pd}(3)$ atoms.
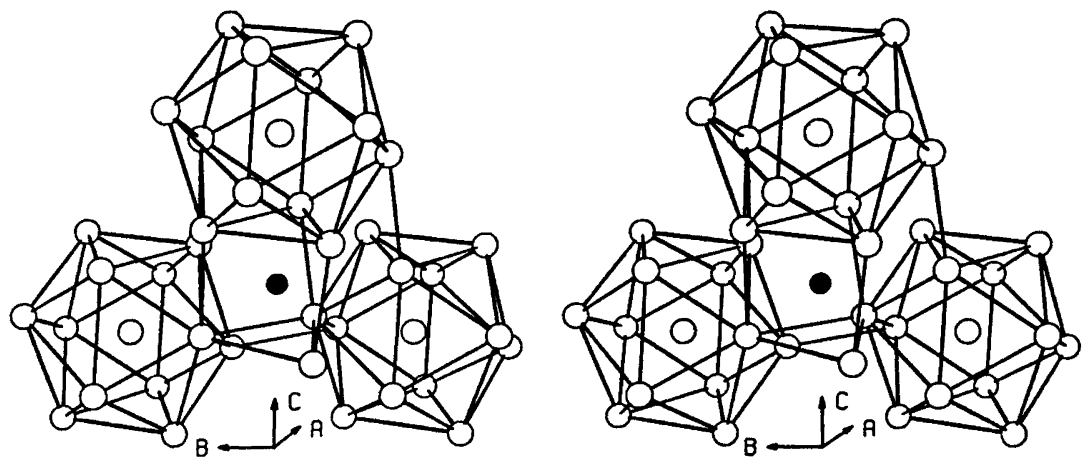

Fig. 2. The "tetrahedral hole" and the environment of the phosphorus atom. For clarity, only one atom of the fourth icosahedron is represented.

of the phosphorus atom is very common in metal-rich transition metal phosphide structures and has been discussed in detail earlier.,8 In particular it occurs ${ }^{10-12}$ in the three palladium phosphides $\mathbf{P d}_{4,8} \mathrm{P}, \mathrm{Pd}_{3} \mathrm{P}$ and $\mathbf{P d}_{8} \mathrm{P}$.

The palladium polyhedron enclosing the central phosphorus atom is built up of the four surrounding palladium icosahedra in the following way. One triangular face of the triangular prism is identical with a triangular face of one of the icosahedra. The second triangular face of the prism is formed by one corner atom from each of the three remaining icosahedra, which also each contribute one of the palladium atoms outside the quadrilateral faces of the prism.

Geometrically, the $\operatorname{Pd}_{15} P_{2}$ structure is closely related to the rhombohedral $\alpha$-boron ${ }^{13}$ struc- ture, where boron icosahedra are packed in a slightly deformed cubic close-packing. Matkovich et al. ${ }^{14}$ have discussed this kind of packing model in detail. $\alpha$-Boron crystallizes in space group $R \overline{3} m$ with the hexagonal unit-cell axes $a=4.908 \AA$ and $c=12.567 \AA$.

In interstitial compounds derived from $\alpha$ boron, ${ }^{16,16}$ for instance $\mathrm{B}_{12} \mathrm{C}_{2}$ and $\mathrm{B}_{13} \mathrm{C}_{2}$, the "octahedral holes" enclose two to three interstitial atoms, while the "tetrahedral holes" are empty.

Acknowledgements. The author wishes to thank Professor I. Olovsson for all the facilities provided and is deeply indebted to Professor S. Rundqvist for valuable discussions and comments. Financial support from the Swedish Natural Science Research Council is gratefully acknowledged. 


\section{REFERENCES}

1. Gullman, L.-O. J. Less-Common Met. 11 (1966) 157.

2. Deslattes, R. D. and Henins, A. Phys. Rev. Lett. 31 (1973) 972.

3. Ersson, N.-O. Institute of Chemistry, University, Uppsala 1973. Unpublished.

4. Malmros, G. and Werner, P.-E. Acta Chem. Scand. 27 (1973) 493.

5. Lundgren, J.-O., Ed., Crystallographic Computer Programs, Institute of Chemistry, University, Uppsala 1975, UUIC-B13-04-2.

6. International Tables for X-Ray Crystallography, Kynoch Press, Birmingham 1974, Vol. IV.

7. Coppens, P. and Hamilton, W. C. Acta Crystallogr. A 26 (1970) 71.

8. Rundqvist, S. Ark. Kemi 20 (1962) 67.

9. Lundström, T. Ark. Kemi 31 (1969) 227.

10. Sellberg, B. Acta Chem. Scand. 20 (1966) 2179.

11. Rundqvist, S. and Gullman, L.-O. Acta Chem. Scand. 14 (1960) 2246.

12. Andersson, Y., Kaewchansilp, V., del Rosario Casteleiro Soto, M. and Rundqvist, S. Acta Chem. Scand. A 28 (1974) 797.

13. Decker, B. F. and Kasper, J. S. Acta Crystallogr. 12 (1959) 503.

14. Matkovich, V. I., Giese, Jr., R. F. and Economy, J. Z. Kristallogr. 122 (1965) 116.

15. Economy, J., Matkovich, V. I. and Giese, Jr., R. F. Z. Kristallogr. 122 (1965) 248.

16. Will, G. and Kossobutzki, K. H. J. Less Common Met. 44 (1976) 87.

Received January 3, 1977. 